\title{
Infección por el virus de la hepatitis $\mathrm{Cy}$ riesgo de transmisión en cirugía oral
}

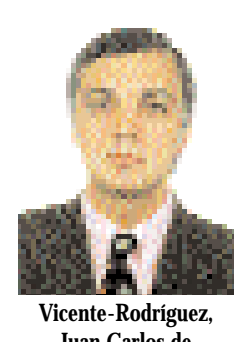

Juan Carlos de

\section{Hepatitis C virus infection and risk of transmission in oral surgery}

\section{Vicente-Rodríguez, u uan Carlos de* | unquera-Gutiérrez, Luis Manuel* López-Arranz, | van Sebastián **}

\author{
*Profesores Titulares Vinculados \\ ** Catedrático Vinculado de Cirugía \\ Oral y Maxilofacial. \\ Servicio de Cirugía Oral y Maxilofacial. \\ Hospital Universitario Central de Astu- \\ rias. Departamento de Cirugía y Espe- \\ cialidades Médico-Quirúrgicas. \\ Facultad de Medicina de Oviedo.
}

Resumen: La hepatitis viral es la principal causa de enfermedad hepatica. Aproximadamente el $85 \%$ de los individuos infectados por el virus de la hepatitis C (VHC) progresa a una infección crónica y, de estos, entre el 1 y el $4 \%$ cada año desarrolla un carcinoma hepatocelular. Además de la lesión hepática, el virus $C$ puede afectar a tejidos y órganos extrahepáticos dando lugar a diferentes manifestaciones, como el líquen plano oral, sialadenitis y quizá cáncer oral.

El objetivo de este trabajo es revisar el riesgo ocupacional de la infección por VHC entre dentistas y cirujanos orales. Ambos deben saber como incorporar el diagnóstico de infección por VHC en el plan de tratamiento quirúrgico programado. También se revisarán la historia natural y la transmisión de este virus vehiculizado por la sangre.

Palabras clave: Virus de la hepatitis C, Cirugía oral, Riesgo de transmisión.

\section{Abstract:}

Viral hepatitis is the most important cause of liver disease. Approximately $85 \%$ of the individuals infected with hepatitis $\mathrm{C}$ virus (HCV) progress to chronic infection and each year $1-4 \%$ of these develop hepatocellular carcinoma. Furthermore, infection with HCV may affect not only the liver but also several nonhepatic tissues and organs showing different manifestations as oral lichen planus, sialadenitis and perhaps oral cancer.

The purpose of this article is to review the occupational risk of HCV infection among dentists and oral surgeons. Both of them should know how to incorporate the diagnosis of HCV infection into the plan for the proposed surgery. We also will review the natural history and transmission of the infection with this blood-borne virus.

Key words: Hepatitis C virus, Oral surgery, Risk of transmission.

\begin{tabular}{ccc}
\hline Fecha recepción & Fecha última revisión & Fecha aceptación \\
$28-11-2002$ & $31-03-2003$ & $21-04-2003$ \\
\hline
\end{tabular}

BIBUD [1138-123X (2003)8:3; mayo-junio 245-348]

Vicente-Rodríguez J C de, J unquera-Gutiérrez LM, López-Arranz J S. Infección por el virus de la hepatitis $\mathrm{C}$ y riesgo de transmisión en cirugía oral. RCOE 2003;8(3):317-324. 


\section{Introducción}

La hepatitis viral es la principal causa de enfermedad hepática en el mundo. Existen cinco tipos de virus, que se designan con las letras mayúsculas A, B, C, D y E; responsables de aproximadamente el 95\% de las infecciones hepáticas virales. De todas ellas, la ocasionada por el virus de la hepatitis $\mathrm{C}(\mathrm{VHC})$, que antes de ser identificado se incluía en el grupo «hepatitis no A-no B», se hizo aparente en la clínica a comienzos de la década de los 60 , en relación con transfusiones de sangre y uso de drogas por vía parenteral, si bien la naturaleza del problema solo se aclaró después de 1990, cuando se dispuso por primera vez de pruebas diagnósticas fiables ${ }^{1}$. En el momento presente se estima que existen 170 millones de personas infectadas en el mundo por el VHC, lo que representa una pandemia viral de magnitud superior a la causada por el $\mathrm{VIH}-1^{2^{*}}$. Estas cifras determinan que entre el $1 \%$ y el $2 \%$ de la población se halla infectada por el VHC, si bien su prevalencia entre los pacientes que acuden a servicios quirúrgicos puede ser más elevada. En consecuencia, los cirujanos y dentistas, así como el personal auxiliar, se encuentran expuestos al riesgo de transmisión de este virus a través de la sangre de sus pacientes, lo que justifica, en nuestra opinión, la necesidad de conocer la naturaleza del VHC, sus vías de transmisión, su ciclo vital y sus manifestaciones clínicas.

El propósito del presente trabajo consiste en revisar los aspectos clínicos de la hepatitis $C$, de interés para el odontólogo o estomatólogo general, haciendo especial hincapié en el ries- go existente de transmisión de esta enfermedad durante los actos quirúrgicos realizados en la cavidad oral.

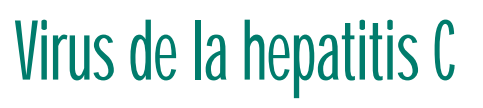

EI VHC es un virus RNA lineal monocatenario perteneciente a la familia de los Flaviviridae. Su genoma contiene unos 10.000 nucleótidos ${ }^{3}$, siendo una característica suya la presencia de un largo marco de lectura abierta (gen) que codifica la síntesis de una poliproteína viral de 3.011 aminoácidos (fig. $1)$ la cual es procesada en al menos 10 polipéptidos discretos, por medio de una peptidasa celular y dos proteasas virales, la NS2-3 autoproteasa y la NS3-4A serín-proteasa. Esto da como resultado la producción de la proteína de la cápside, dos glicoproteínas de la envuelta (E1 y E2), una pequeña proteína hidrofóbica ( $p 7)$ y seis proteínas no estructurales (NS2, NS3, NS4A, NS4B, NS5A y NS5B). Dos regiones de la proteína E2 (regiones hipervariables 1 y 2) exhiben una extremadamente elevada incidencia de mutaciones, probablemente en respuesta a la acción de anticuerpos elaborados por el huésped. E2 también contiene un sitio de unión para CD81, una tetraspanina encontrada en la superficie de muchas células, entre ellas los hepatocitos y, que se supone, actúa como receptor o correceptor para la entrada del virus en las células del hospedador. La replicación del RNA del VHC es proclive al error, debido a que la RNA polimerasa viral carece de mecanismo de corrección de pruebas, lo que contribuye a la diversidad genética de este virus, dentro de la cual se distinguen cuatro estratos jerárqui- cos: genotipos, subtipos, aislados y cuasiespecies. El aumento de la diversidad viral, manifestado en una abundancia de cuasiespecies en la misma persona infectada, representa un gran obstáculo para el control del virus por el sistema inmune $y$, durante la fase de infección aguda, se asocia con la progresión de la hepatitis a la cronicidad, mientras que la relativa estabilidad de las cuasiespecies se asocia con resolución de la hepatitis aguda ${ }^{4}$. Los pacientes que responden favorablemente al tratamiento con interferón también poseen una escasa diversidad genética viral. Se distinguen seis genotipos diferentes del VHC, distribuidos de forma desigual a lo largo del mundo. En Europa occidental y EEUU predominan los genotipos $1 a$ y $1 b$, seguidos por los genotipos 2 y 3. En Egipto predomina el genotipo 4. En Sudáfrica el 5 y en el sudeste asiático el 6. Estos genotipos poseen valor predictivo de la respuesta a la terapia viral, siendo mejores las respuestas observadas con los genotipos 2 y 3 que con el 1 .

Las células diana del VHC son los hepatocitos, de los que están infectados por el virus el $50 \%$ o más, y quizá también los linfocitos $\mathrm{B}^{2 *}$. La replicación viral es extremadamente profusa, siendo del orden de $10^{12}$ partículas virales por día ${ }^{5}$, incluso en la fase crónica.

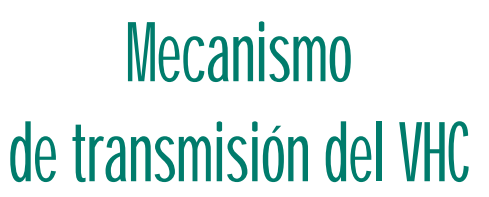

A pesar de que en los comienzos de la expansión de la enfermedad fue la vía principal, actualmente las transfusiones de sangre representan un 


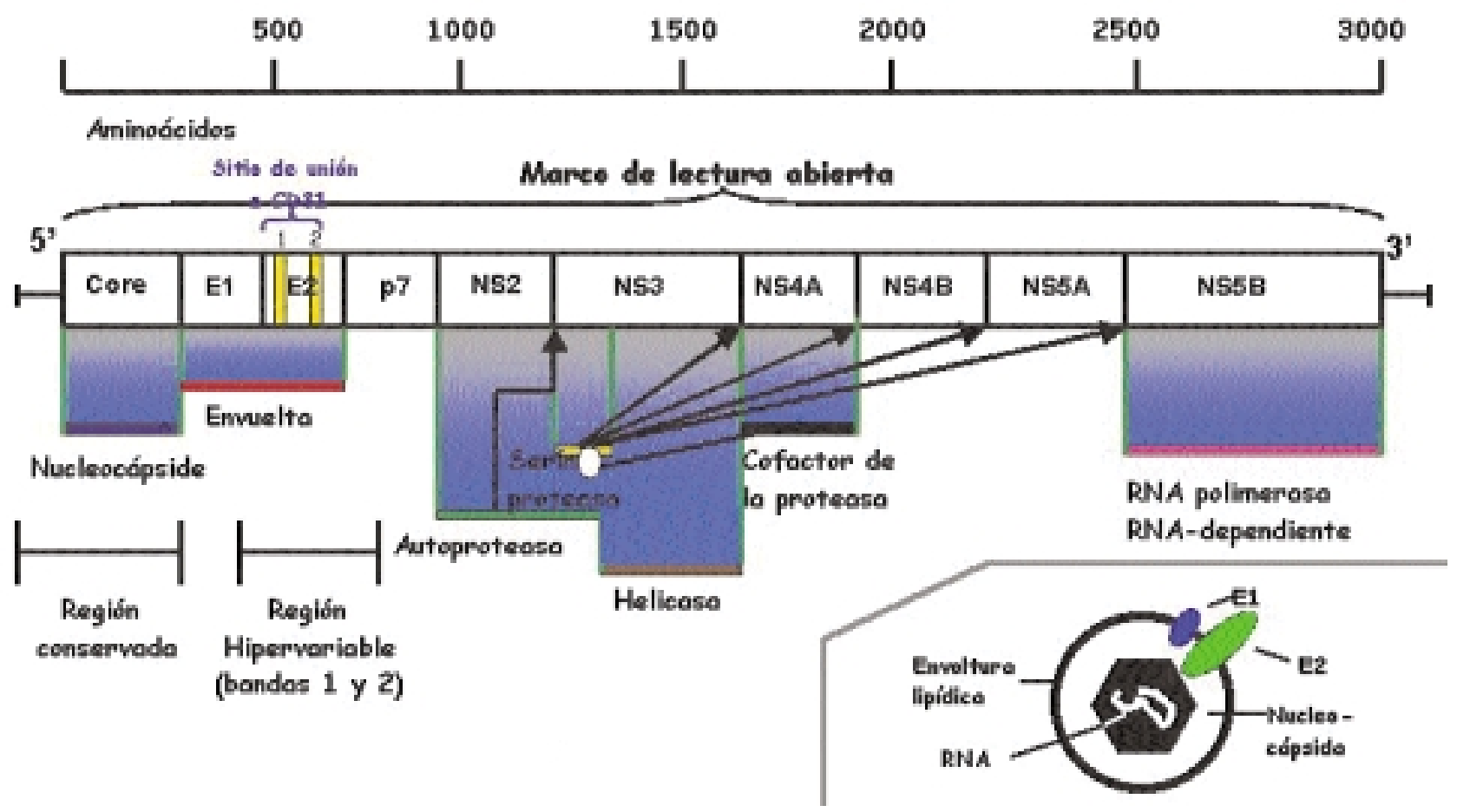

Figura 1: Estructura del VHC.

mecanismo de transmisión muy infrecuente en nuestro medio, de modo que la mayor parte de los nuevos casos son debidos al uso de drogas por vía parenteral y, en menor grado, a exposición percutánea o mucosa a sangre contaminada con el VHC. Desde la introducción del estudio sistemático de anticuerpos anti-VHC en la sangre destinada a transfusiones, la frecuencia de transmisión por esta vía se ha reducido hasta aproximadamente 1 caso por cada 103.000 unidades transfundidas ${ }^{6}$. La razón de que este riesgo no sea nulo es que la sangre destinada a ser transfundida ha podido ser obtenida de un individuo en el «periodo ventana», extendido entre el momento de la infección por el virus y el desarrollo de anticuerpos, lo que se estima que ocurre en menos de 12 semanas. Este riesgo puede ser actualmente reducido mediante la utilización de la reacción en cadena de la polimerasa (PCR) con la que se reduciría el periodo ventana a unas tres semanas, pero aún manteniendo las cifras referidas, este riesgo es la mitad del observado en la transmisión del virus de la hepatitis B (VHB) (1 caso de cada 63.000 unidades de sangre transfundidas), pero casi 5 veces superior que el de la transmisión del VIH (1 en cada 493.000) ${ }^{6}$. Los factores de riesgo de infección por el $\mathrm{VHC}$ han sido estudiados en lugares geográficos distantes, existiendo similitudes y diferencias entre los mismos. Medhat et $\mathrm{al}^{7}$, en una localidad del norte de Egipto con una moderadamente elevada prevalencia de infección por el VHC $(8,7 \%)$, estudiaron una muestra representativa del $63 \%$ de la población (6.012 sujetos) mediante un cuestionario sobre hábitos de riesgo y un análisis de muestras serológicas para detección de anticuerpos anti-VHC. Los riesgos que identificaron en un análisis multivariante fueron los siguientes: terapia parenteral previa para esquistosomiasis, transfusiones de sangre, circuncisión realizada por personal no sanitario e infecciones frecuentes. Los antecedentes de tratamientos dentales no se correlacionaron con una mayor prevalencia de infección por el VHC. Urbanek et $\mathrm{al}^{8}$ estudiaron, en la República Checa, un grupo de 216 individuos con infección documentada por el VHC, identificando los siguientes factores de riesgo, con sus respectivas frecuencias: transfusión de sangre (15\%), inyec- 
ción de drogas por vía intravenosa (16\%), inclusión en un programa de diálisis regular (12\%), transmisión relacionada con la profesión (10\%), contacto sexual con individuos infectados $(2 \%)$, cirugía, incluyendo cirugía dental (14\%), exploraciones invasivas (6\%) y tatuajes (1\%). En el $24 \%$ de los casos no pudieron identificar los factores de riesgo. De las cifras precedentes se desprende que, en el $57 \%$ de los pacientes de este estudio, la infección fue iatrogénica, incluyendo la práctica de cirugía oral.

Riestra et $\mathrm{al}^{9}$ estudiaron una muestra de 1.170 individuos en el norte de España (Asturias) para determinar: (i) prevalencia de la infección por VHC, (ii) factores de riesgo asociados con la misma y, (iii) distribución de genotipos virales. Diecinueve individuos de la muestra $(1,6 \%)$ fueron anti-VHC positivos, habiéndose en-contrado el genotipo $1 \mathrm{~b}$ en el $80 \%$ de ellos. Los únicos factores de riesgo identificados fueron el abuso de drogas por vía parenteral (pacientes en la cuarta década de la vida) y los antecedentes de intervenciones quirúrgicas y transfusiones de sangre (en individuos de más de 60 años).

La transmisión por contacto sexual del VHC, si bien es posible, resulta altamente improbable, seguramente por la baja concentración de virus en los fluidos genitales y tal vez por la ausencia de células diana adecuadas en el tracto genital. La coinfección con el $\mathrm{VIH}-1$, parece incrementar el riesgo de transmisión por vía sexual o materno-fetal del VHC. Si bien el virus puede ser aislado de la saliva de personas infectadas ${ }^{10}$, y a pesar de que se ha logrado infectar chimpancés mediante la inyección de saliva humana portadora del VHC, se admite que la saliva no es un vehículo capaz de transmitir la infección en contactos casuales. Aproximadamente en el $10 \%$ de los casos, el origen de la infección es desconocido ${ }^{11}$, no pudiendo identificarse ninguno de los factores de riesgo precitados. De la infección transmitida en el curso de la práctica quirúrgica y odontológica, nos ocuparemos posteriormente.

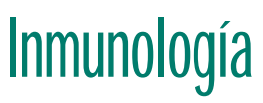

La respuesta inmune al VHC parece ser crítica para determinar el aclaramiento del virus tras la infección, o por el contrario, su persistencia. La presencia en la sangre circulante de linfocitos $\mathrm{T}$ citotóxicos específicos frente al VHC es baja, representando solamente el $0,01 \%$ al $0,5 \%$ de los linfocitos $\mathrm{T} \mathrm{CD} 8+{ }^{12}$. Por el contrario, la presencia de linfocitos $T$ específicos frente al VHC en el hígado, es notablemente elevada. Estos linfocitos $T$ CD8+ funcionalmente deficientes, son $\mathrm{CD} 27+$, pero $\mathrm{CD} 28$ - y parecen sufrir de una falta de actividad $\mathrm{T}$ helper CD4 $4^{13}$.

La curación de la infección por el VHC se halla asociada con un incremento en la respuesta de los linfocitos $\mathrm{T}$, mientras que la infección crónica está signada por una reducción en la producción linfocitaria de interferón gamma. La relativamente pobre respuesta de los linfocitos $\mathrm{T}$ citotóxicos en pacientes con hepatitis C crónica, parece ser insuficiente para contener la viremia y la evolución genética del virus, pero suficiente para causar un daño hepático colateral mediante la elaboración de citoquinas.
Si bien no ha sido suficientemente estudiada, se supone que la respuesta humoral también juega un papel importante en la eliminación del VHC.

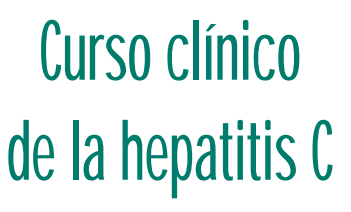

La hepatitis por virus $C$ es raramente diagnosticada durante la fase aguda de la enfermedad, careciendo la mayoría de los pacientes de manifestaciones clínicas, incluso discretas. Cuando éstas se presentan, lo hacen entre 7 y 8 semanas (rango de 2 a 26) tras la exposición al VHC, y suelen consistir en ictericia, malestar y náuseas. Tras las fases iniciales de la enfermedad, entre el 74 y el $86 \%$ de los sujetos padecerán una viremia persistente, siendo usual la evolución a la cronicidad, en cuyas fases finales, el 15 a $20 \%$ de los infectados alcanzarán un estado de cirrosis hepática ${ }^{14}$. El tiempo transcurrido entre la infección y el desarrollo de cirrosis puede superar los 30 años, lo que unido al usualmente subclínico inicio del proceso, hace que sea difícil llevar a cabo estudios longitudinales prospectivos. No obstante, el tiempo de evolución de la enfermedad, o el que tardan en desarrollarse sus diversas fases varía de unos pacientes a otros, acelerándose su curso en presencia de diversos factores, como consumo de alcohol, coinfección con otros virus ( $\mathrm{VIH}, \mathrm{VHB})$, sexo masculino y edad avanzada en el momento de la infección. De particular interés es el hecho de que la coexistencia del VHC con otros virus agrava el curso evolutivo de la enfermedad. Por ejemplo, la asociación de VHC y $\mathrm{VIH}-1$ eleva el ries- 


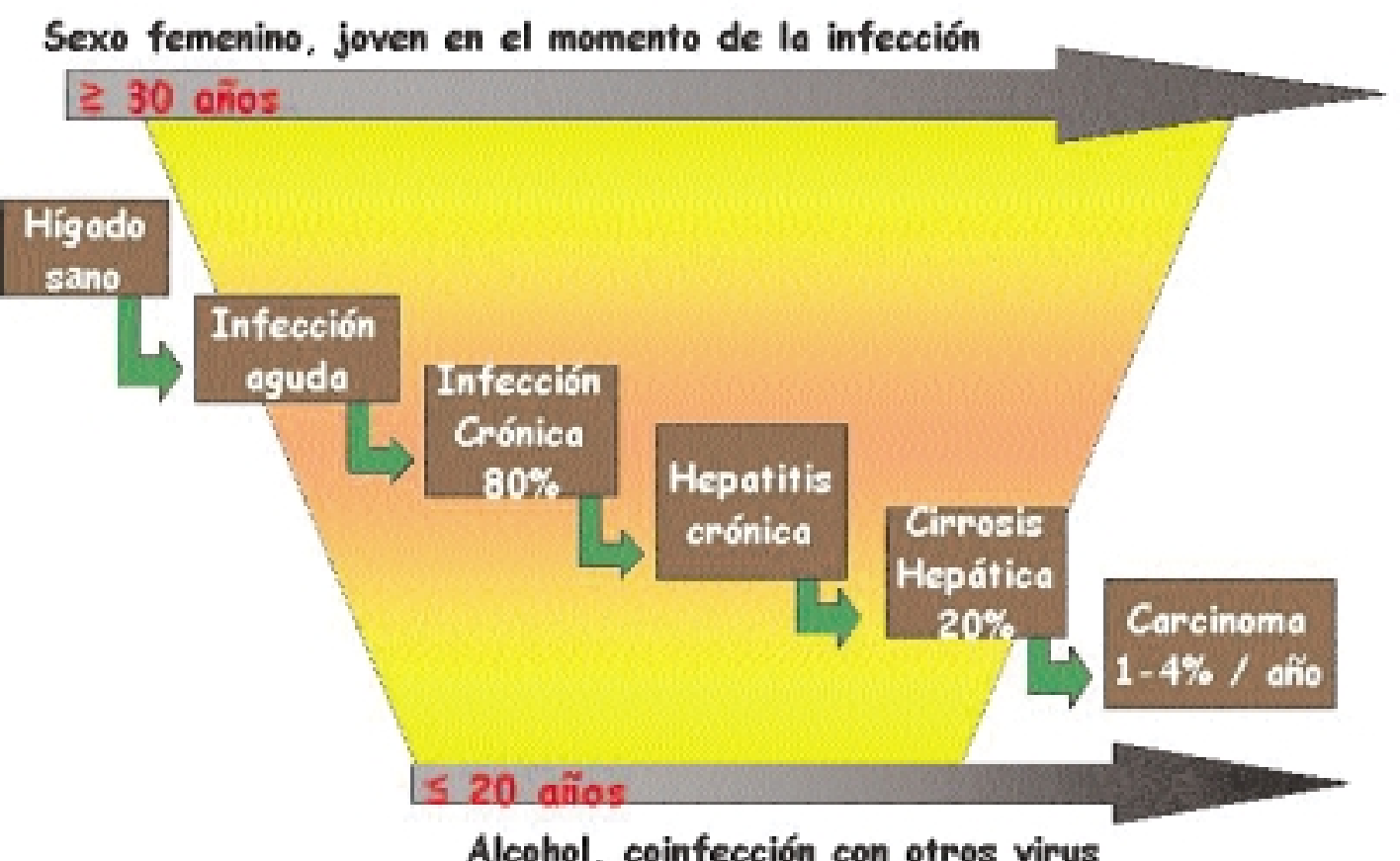

Figura 2: Curso clínico de la infección por el VHC.

go de cirrosis a los 15 años de la infección al $25 \%$ en comparación con el $6,5 \%$ encontrado en los pacientes infectados solamente por el VHC.

En síntesis, la evolución de la enfermedad puede ser esquematizada de la siguiente forma (fig. 2):

Hepatitis aguda: el $85 \%$ de los pacientes siguen un curso asintomático. También un 85\%evoluciona a la cronicidad.

Hepatitis crónica: el $25 \%$ de los pacientes siguen una evolución benigna, con transaminasas normales; el $20 \%$ de los que llegan a la fase de enfermedad crónica desarrollan una cirrosis hepática en un plazo de 20 a 30 años $y$, de los que desarrollan una cirrosis, el 1\%- 4\% por año ${ }^{15}$ sufren un carcinoma hepatocelular. La prevalencia de carcinoma entre los pacientes aquejados de hepatitis $C$ crónica se estima en un 0,4 a 2,5\%1․ Las características clínicas de la enfermedad por virus $C$ son resumidas comparativamente con las de otros virus hepatotropos, en la tabla 1.

Pero, además de la afectación hepática, el VHC puede ocasionar manifestaciones extrahepáticas, principalmente asociadas con trastornos autoinmunes o con procesos linfoproliferativos. Entre ellas, destacan las siguientes: crioglobulinemia esencial, glomerulonefritis membranoproliferativa, tiroiditis de Hashimoto, síndrome de sicca, sialadenitis, porfiria cutánea tarda, trombopenia idiopática, diabetes, ulceración corneal, uveitis, líquen plano, linfomas no-Hodgkinianos ${ }^{16}$ y quizá cáncer oral ${ }^{17}$. Las manifestaciones extrahepáticas pueden resultar de mecanismos inmunológicos, así como de la invasión y replicación del virus en los tejidos y órganos afectados. Entre el $36 \%$ y el $45 \%$ de los pacientes infectados por el VHC poseen crioglo- bulinas, si bien solo el 10 o 15\%tienen enfermedad sintomática. Las crioglobulinas son inmunocomplejos (generalmente complejos lgG IgM) que precipitan con el frío, causando púrpura, artralgias, neuropatía, fenómeno de Raynaud y, en los casos más severos, glomerulonefritis membranoproliferativa. La infección por el VHC es responsable del 80 a $90 \%$ de los casos de crioglobulinemia mixta esencial.

\section{Transmisión nosocomial

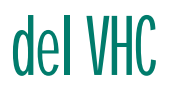

La infección en ambientes hospitalarios ha sido documentada tanto entre pacientes (transfusión de sangre y derivados, trasplante de órganos, diálisis, colonoscopia, utilización de catéteres intravenosos, circuitos 


\begin{tabular}{|c|c|c|c|c|c|}
\hline Característica & VHA & VHB & VHC & VHD & VHE \\
\hline Tipo de virus & Hepatovirus (RNA) & Hepadnavirus (DNA) & Flavivirus (RNA) & Virus RNA defectivo & Calicivirus (RNA) \\
\hline Transmisión & Fecal-oral & $\begin{array}{l}\text { Parenteral, } \\
\text { Sexual, } \\
\text { Perinatal Per }\end{array}$ & $\begin{array}{c}\text { Parenteral, } \\
\text { Sexual (?) } \\
\text { arinatal (infrecuente }\end{array}$ & $\begin{array}{l}\text { Parenteral, } \\
\text { Sexual, } \\
\text { Perinatal }\end{array}$ & Fecal-oral \\
\hline Incubación (días) & 15 - 50 (media: 30) & 30 - 180 (media: 60-90) & )15 - 180 (media: 50) & 30 - 180 (media: 60 - 90) & 15 - 60 (media: 40) \\
\hline Comienzo & Agudo & Agudo / insidioso & Insidioso & Agudo / insidioso & Agudo \\
\hline $\begin{array}{l}\text { Clínica } \\
\text { - Gravedad } \\
\text { - Fulminante } \\
\text { - Cronicidad } \\
\text { - Cáncer }\end{array}$ & $\begin{array}{l}\text { Leve } \\
0,1 \% \\
\text { No } \\
\text { No }\end{array}$ & $\begin{array}{c}\text { Leve / Grave } \\
0,1-1 \% \\
1-10 \% \\
\pm\end{array}$ & $\begin{array}{c}\text { Moderada } \\
0,1 \% \\
85 \%(>70 \%) \\
+\end{array}$ & $\begin{array}{c}\text { Leve / Grave } \\
5-20 \% \\
\text { Frecuente } \\
\pm\end{array}$ & $\begin{array}{l}\text { Leve } \\
1-2 \% \\
\text { No } \\
\text { No }\end{array}$ \\
\hline Diagnóstico & $\begin{array}{l}\text { IA**: IgM anti-VHA } \\
\text { IC: IgG anti-VHA }\end{array}$ & $\begin{array}{c}\text { IA: IgM anti-HBc } \\
\text { HBsAg (90\%) } \\
\text { IC: IgG anti-HBc } \\
\text { HBsAg } \\
\text { arcadores de replicacić } \\
\text { HbeAg } \\
\text { DNA-VHB }\end{array}$ & $\begin{array}{l}\text { IC: anti-VHC乡 } \\
\text { RNA-VHC } \\
\text { ión: }\end{array}$ & $\begin{array}{l}\text { Anti-VHD } \\
\text { RNA-VHD }\end{array}$ & $\lg M / \lg G$ anti-VHE \\
\hline Pronóstico & Excelente & Reservado & Reservado & Bueno (IA), Malo (IC) & Bueno \\
\hline Profilaxis & $\begin{array}{l}\text { Vacuna recombinante } \\
\text { lg postexposición }\end{array}$ & $\begin{array}{l}\text { Vacuna recombinante } \\
\text { lg anti-B postexposición }\end{array}$ & No & Vacuna del VHB & No \\
\hline Tratamiento & No & $\begin{array}{l}\text { Interferón (INF)- } \alpha \\
\text { (eficacia del } 40 \% \text { ) }\end{array}$ & $\begin{array}{l}\text { INF } \alpha+\text { ribavirina } \\
\text { (eficacia }>50 \% \text { ) }\end{array}$ & No & No \\
\hline
\end{tabular}

de respiración y viales multidosis), como de pacientes a personal sanitario y de éste hacia aquellos. En relación con esta última posibilidad, hemos recogido cinco casos publicados; uno en España, en el que un cirujano infectado por el virus lo transmitió a 5 pacientes ${ }^{18}$, otro en el Reino Unido, consistente en la transmisión del VHC por un cirujano cardiaco a un paciente ${ }^{19}$, y un tercero, en el que un anestesista alemán contrajo el VHC a partir de un paciente y lo transmitió a otros cinco ${ }^{20}$. Cody et $\mathrm{a}^{21}$ han referido el caso de un anestesista norteamericano aquejado de una hepatitis aguda por VHC, contagiado 9 semanas antes por un paciente y que, a su vez, la transmitió a otro paciente durante la anestesia efectuada en el curso de una toracotomía. Finalmente, otro caso acontecido en España ${ }^{22}$, involucró a un anestesista adicto a narcóticos, que se inyectó a si mismo el fármaco destinado a un paciente, antes de administrarle a este el resto de la dosis, empleando para ello la misma aguja y jeringa.
La transmisión entre pacientes en un contexto hospitalario es improbable cuando se siguen las normas profilácticas básicas de actuación profesional. Enomoto et $a^{23^{2 *}}$ estudiaron la posibilidad de transmisión nosocomial del VHC en servicios de cirugía y dentales hospitalarios, determinando anticuerpos anti-VHC; VHC-RNA y analizando la región hipervariable 1 (HVR1) en el RNA viral. Cinco pacientes fueron VHC positivos en un servicio de cirugía, 6 en un hospital dental y 9 en otro. Las cuasiespecies virales fueron 
diferentes de unos pacientes a otros, por lo que en el contexto del estudio no se identificó transmisión de pacientes entre si.

Sin embargo, y en relación con el objetivo del presente trabajo, nos interesa particularmente la transmisión del VHC de pacientes a personal sanitario, habitualmente mediante pinchazos accidentales con agujas de sutura o huecas, empleadas estas últimas para administrar fármacos 0 recoger muestras biológicas, circunstancia que afecta principalmente a cirujanos, ginecólogos y dentistas. En un estudio prospectivo de más de 1.300 procedimientos quirúrgicos, se observó la preocupante frecuencia de lesiones percutáneas accidentales en el 6,9\% $\%^{4}$. El riesgo de transmisión de la infección por VHC en estos casos oscila entre un 0 y un $10 \%$ si bien depende del tamaño del inóculo (carga viral, aguja hueca o maciza, tamaño de la aguja) y de la profundidad de inoculación. Ante un «pinchazo» accidental, y para anticipar el riesgo de infección, puede ser útil recordar la regla de «los treses»: el VHB es transmitido en el $30 \%$ de los casos, el $\mathrm{VHC}$ en el $3 \%$ y el $\mathrm{VIH}$ en el $0,3 \%$

Con la intención de evaluar el riesgo de transmisión parenteral de hepatitis, Mele et $a^{25^{2}}$ estudiaron de forma prospectiva 3.120 casos de hepatitis $B$ y 1.023 de hepatitis $C$, relacionándolos con diversos procedimientos quirúrgicos, en un intento de evaluar riesgos específicos mediante el cálculo de odds ratio (OR). Las asociaciones observadas para la hepatitis B fueron: cirugía abdominal $(O R=3,9)$, cirugía oral $(O R=2,7)$ y cirugía ginecológica $(\mathrm{OR}=2,6)$. Para la hepatitis $C$, se observó asociación con: intervencio- nes obstétrico-ginecológicas $(\mathrm{OR}=$ $2,1)$, cirugía abdominal $(O R=7,0)$ y cirugía oftalmológica $(O R=5,2)$.

En el contexto de la presente exposición resulta interesante conocer la prevalencia de pacientes seropositivos en un gabinete de cirugía oral y maxilofacial. Así, Dreyer et $\mathrm{al}^{26}$ estudiaron en Sudáfrica 180 pacientes sometidos a cirugía oral, observando las siguientes frecuencias de seropositividad entre los mismos: $\mathrm{VIH}, 1,1 \%$ VHB, 2,8\% y VHC, 1,1\% En un área geográfica muy diferente (Grecia), Lionis et $a^{27}$ estudiaron 1961 pacientes que visitaron consultas de medicina general. La prevalencia de infección por VHC entre ellos fue del 3,5\% Mediante un análisis multivariante, se detectaron unas variables relacionadas con la infección por el VHC: antecedentes de cirugía oral, adicción a drogas por vía intravenosa, ingreso hospitalario de más de 7 días y alto consumo de alcohol. En Japón, Komori et $\mathrm{al}^{28}$ encontraron una prevalencia del 3,2\%de seropositividad para VHC entre los pacientes de una consulta de cirugía oral.

Estos resultados muestran que, independientemente del lugar geográfico considerado, la prevalencia de la infección por VHC es lo suficientemente importante como para que los dentistas y cirujanos adopten medidas universales de precaución en el curso de sus actos quirúrgicos, ya que una proporción significativa de los pacientes que deben atender es potencialmente transmisora de infecciones graves, como la causada por el VHC. Y como además no es posible identificar a los pacientes infectados (salvo que ellos lo sepan y lo comuniquen en la anamnesis previa al acto quirúrgico), todos los pacientes deben ser considerados potencialmente infecciosos.

Para ponderar el impacto de esta enfermedad en la profesión, Thomas et al $^{29^{* *}}$ evaluaron, en 343 cirujanos orales y 305 dentistas norteamericanos, la prevalencia de infección por el VHC, determinada mediante enzimoinmunoanálisis e inmunoblot recombinante. Las prevalencias observadas fueron: $2 \%$ en cirujanos orales y $0,7 \%$ en dentistas generales. Los anticuerpos anti-VHC se observaron con mayor frecuencia en dentistas y cirujanos de mayor edad, con más años de práctica profesional y marcadores serológicos de infección por el VHB (estos fueron encontrados en el 7,8\% de los dentistas generales y en el $21,2 \%$ de los cirujanos orales).

Los dentistas y cirujanos orales se enfrentan, en el ejercicio de su profesión, no solo a sangre, sino a otros fluidos, como la saliva. Si bien la sangre es el vehículo principal del VHC, este se halla presente en la saliva de menos del $25 \%$ de las personas con virus en el torrente sanguíneo y, aún en ellos, está restringido a la fracción celular de la secreción. Por ello, como ya ha sido referido, la saliva contiene virus, a pesar de lo cual se estima que su capacidad infectante es muy baja, incluso insignificante. No obstante, la contaminación de la saliva con sangre, como ocurre tras intervenciones de cirugía oral, incrementa el riesgo de exposición viral para los dentistas y cirujanos, de ahí que el conocimiento de los patógenos transmisibles por la sangre y sus derivados, así como de las graves consecuencias potenciales para su salud, sea de vital importancia para ellos. 
Y para los dentistas y cirujanos que estén infectados por el VHC, tiene interés saber que las guías actuale $^{30}$ para la prevención de la transmisión de patógenos vehiculizados por la sangre desde trabajadores sanita- rios a pacientes, no recomiendan la restricción de las actividades profesionales de trabajadores infectados por este virus. No obstante, es preciso que todos los trabajadores sanitarios sigan una técnica estrictamente aséptica y adopten las precauciones estándar, incluyendo un adecuado lavado de manos, el uso de barreras protectoras y el manejo cuidadoso de agujas e instrumentos cortantes.

\section{Bibliografía recomendada}

Para profundizar en la lectura de este tema, el/los autor/es considera/an interesantes los artículos que aparecen señalados del siguiente modo: *de interés ${ }^{* *}$ de especial interés.

1. Wasley A, Alter MJ. Epidemiology of hepatitis C: Geographic differences and temporal trenes. Semin Liver Dis 2000;20:1-13.

2*. Lauer GM, Walker BD. Hepatitis C virus infection. N Engl J Med 2001;345:41-52.

Artículo de revisión en el que se presentan, de forma detallada, clara y actualizada, todos los aspectos relevantes de la infección por el VHC.

3. Liang JT, Thompson M. Molecular biology of hepatitis $\mathrm{C}$ virus. En: Liang TJ, Hoofnagle JH, eds. Hepatitis C. San Diego: Academic Press, 2000:1-24.

4. Farci P, Shimoda A, Coiana A, et al. The outcome of acute hepatitis $C$ predicted by the evolution of the viral quasiespecies. Science 2000;288:339-44

5. Neumann AU, Lam NP, Dahari H, et al. Hepatitis $\mathrm{C}$ viral dynamics in vivo and the antiviral efficacy of interferon-alpha therapy. Science 1998;282:103-7.

6. Schreiber GB, Busch MP, Kleinman SH, Korelitz $\mathrm{JJ}$. The risk of transfusion-transmitted viral infections. N Eng J Med 1996;334:1685-90.

7. Medhat A, Shehata M, Magder LS, et al. Hepatitis $\mathbf{C}$ in a community in Upper Egypt: risk factors for infection. Am $\mathrm{J}$ Trop Med Hyg 2002;66:633-8.

8. Urbanek P, Marecek Z, Brodanova M, Bruha R, Kalab M, Petrtyl J. Risk factors for transmission of hepatitis $\mathbf{C}$ in the $\mathbf{C z e c h}$ population. Cas Lek Cesk 2002;141:185-8.

9. Riestra S, Fernández E, Leiva P, García S, Ocio G, Rodrigo L. Prevalence of hepatitis $\mathrm{C}$ virus infection in the general population of northern Spain. Eur J Gastroenterol Hepatol 2001; 13:46571.

10. Couzigou P, Richard L, Dumas F, Schouler L, Fleury H. Detection of HCV-RNA in saliva of patients with chronic hepatitis C. Gut 1993; 34:Suppl:S59-S60.

11. Massari M, Petrosillo N, Ippolito G, et al. Transmission of hepatitis $\mathbf{C}$ virus in a gynaecological surgery setting. J Clin Microbiol 2001;39:2860-3.

12. He XS, Rehermann B, Boisvert J, et al. Direct functional analysis of epitope-specific CD8+
T cells in peripheral blood. Viral immunology 2001;14:59-69.

13. Di Bisceglie AM, McHutchison J, Rice CM. New therapeutic strategies for hepatitis C. Hepatology 2002;35:224-31.

14. EASL International Consensus Conference on Hepatitis C: Paris, 26-28, February 1999,consensus statement. J Hepatol 1999; 30:956-61.

15. Ikeda K, Saitoh S, Koida I, et al. A multivariate analysis of risk factors for hepatocellular carcinogenesis: a prospective observation of 795 patients with viral and alcoholic cirrhosis. Hepatology 1993;18:47-53.

16. Zuckerman E, Zuckerman T, Levine AM, et al. Hepatitis $C$ virus infection in patients with $B$ cell non-Hodgkin lymphoma. Ann Intern Med 1997;127:423-8.

17. Nagao Y, Sata M, Fukuizumi K, Harada H, Kameyama $\mathrm{T}$. Oral cancer and hepatitis $\mathrm{C}$ virus (HCV): can HCV alone cause oral cancer? a case report. Kurume Med J 1996;43:97-100.

18. Esteban JI, Gomez J, Martell M, et al. Transmission of hepatitis $\mathbf{C}$ virus by a cardiac surgeon. N Engl J Med 1996;334:555-60.

19. Duckworth GJ, Heptonstall J, Aitken C. Transmission of hepatitis $\mathrm{C}$ virus from a surgeon to a patient. Commun Dis Public Health 1999; 2:188-92.

20. Ross RS, Viazov S, Gross T, Hofmann F, Seipp HM, Roggendorf M. Transmission of hepatitis $C$ virus from a patient to an anaesthesiology assistant to five patients. N Engl J Med 2000; 343:1851-4.

21. Cody SH, Nainan OV, Garfein RS, et al. Hepatitis $\mathrm{C}$ virus transmission from an anesthesiologist to a patient. Arch Intern Med 2002; 162:345-50.

22. Bosch $X$. Hepatitis $C$ outbreak astounds Spain. Lancet 1998;351:1415.

23**. Enomoto A, Yoshino S, Hasegawa H, et al. Phylogenetic investigation for the risk of hepatitis $\mathrm{C}$ virus transmission to surgical and dental patients. J Viral Hepat 2001;8:148-53.

Estudio acerca de la transmisibilidad del VHC en pacientes hospitalizados en servicios quirúrgicos y dentales. Mediante el estudio de RNA-VHC y cua- siespecies en los distintos pacientes seropositivos se concluye que el riesgo de transmisión entre pacientes es muy bajo.

24. Tokars JI, Bell DM, Culver DH, et al. Percutaneous injuries during surgical procedures. $\mathrm{J}$ Am Med Assoc 1992;267:2899-904.

25*. Mele A, Spada E, Sagliocca L, et al. Risk of parenterally transmitted hepatitis following exposure to surgery of other invasive procedures: results from the hepatitis surveillance system in Italy. J Hepatol 2001;35(2):284-9.

Estudia los factores de riesgo de la transmisión parenteral del VHC. Mediante un análisis de regresión logística identifica diversos factores y muestra la fuerte asociación existente entre la cirugía oral y el riesgo de infección.

26. Dreyer AF, Aspinall S, Jacobs FJ. Prevalence of markers for human immunodeficiency, hepatitis $B$ and hepatitis $C$ viruses in maxillofacial and oral surgery patients at Medunsa. J Dent Assoc S Afr 1993;48:377-80.

27. Lionis C, Vlachonikolis IG, Skliros S, Symeonidis A, Merkouris BP, Kouroumalis E. Do undefined sources of hepatitis $C$ transmission exist?. The Greek study in general practice. J Viral Hepat 2000;7:218-24

28. Komori T, Matsumoto Y, Yokoyama K, Matsumoto K, Takato T. Study on the positive rate of infectious disease in in-patients at the department of oral surgery. Kokubyo Gakkai Zasshi 1996;63:478-81.

$29 * *$. Thomas DL, Gruninger SE, Siew C, Joy ED, Quinn TC. Occupational risk of hepatitis C infections among general dentists and oral surgeons in North America. Am J Med 1996;100:41-5.

Evalúa el riesgo de transmission del VHC en el personal de clínicas dentales. Confirma la elevada prevalencia de infección por el VHB entre dentistas, pero sugiere que el riesgo de transmisión del VHC es considerablemente menor.

30. Centers for Disease Control and Prevention. Recommendations for prevention and control of hepatitis $\mathrm{C}$ virus (HCV) infection and HCV-related chronic disease. MMWR Morb Mortal Wkly Rep 1998;47(RR-19):1-39.

RCOE, 2003, Vol 8, №3, 317-324 